\title{
Gabriel Comes Nolla (coordinador), Belén Parera Pozuelo, Gemma Vedriell Sánchez i Maria Vives García. (2009). La funció psicopedagògica en l'etapa d'educació secundària obligatòria. Tarragona, AROLA editors.
}

Quan es parla de "la funció psicopedagògica a l'ensenyament secundari obligatori", hom ho relaciona amb la incorporació fa anys del psicopedagog als instituts. Els nens i nenes amb necessitats educatives especials que havien estat atesos a l'ensenyament primari, passaven a l'institut i calia un professional que fos qui vetllés per la seva adaptació, que donés suport al professorat i col-laborés amb les famílies. Aleshores va néixer aquest nou perfil professional als centres de secundària. Un perfil que es combinava de manera poc clara amb els psicopedagogs dels Equips d'Orientació Psicopedagògica. Calia doncs, anar perfilant les funcions de cada un amb l'objectiu de que les seves tasques fossin compatibles i complementàries.

Respecte del nou rol professional incorporat als centres, el Departament d'Ensenyament des de l'inici va voler que aquest professional tingués un marcat caràcter docent i per això l'anomenava "professor de psicologia i pedagogia", i actualment "Professor especialista en orientació educativa". Aquest perfil docent però, de vegades no s'ha ajustat a les necessitats dels centres i no ha seguit la línia d'altres experiències a l'estat i a Europa.

L'atenció a la diversitat de necessitats educatives de l'alumnat a secundària havia de ser responsabilitat de tot el professorat. El professorat de l'especialitat d'orientació educativa i els mestres de pedagogia terapèutica s'han de dedicar, prioritàriament, als alumnes que presenten més dificultats en l'aprenentatge i, molt particularment, a aquells que necessiten suports educatius específics per progressar en els seus aprenentatges i per participar en les activitats ordinàries del centre, complementant les funcions que desenvolupen els professors de cada matèria pel que fa a l'atenció de les diferents capacitats, interessos i ritmes d'aprenentatge que presenten els alumnes. Per tant, els alumnes amb necessitats educatives especials vinculades a discapacitats i els alumnes amb greus dificultats d'aprenentatge són els primers que s'han de beneficiar de la intervenció d'aquests especialistes.

El llibre està organitzat en dues parts de la següent manera: 
- Una primera on es descriu el sistema educatiu espanyol, les característiques de l'educació secundària, el concepte d'educació inclusiva, diferents mesures i recursos organitzatius dels centres i els professionals que treballen al camp de la psicopedagogia.

- La segona on s'aborden de manera clara i entenedora el que anomenen "les creences dels psicopedagogs al voltant de la seva tasca als centres de secundària" on expliquen la investigació realitzada i els resultats obtinguts.

Aquest treball és fruit d'una investigació portada a terme durant els cursos 20052006, 2006-02007 i 2007-2008, va ser possible, gràcies a l'ajut atorgat per la Fundació Propedagògic.

Els autors es proposen com a objectiu principal, conèixer el pensament dels psicopedagogs i psicopedagogues que treballen en centres de secundària de Catalunya, sobre la seva tasca professional.

Per això calia conèixer les actuacions educatives que es realitzen a l'etapa d'educació secundària obligatòria (ESO) per atendre la diversitat de l'alumnat a Catalunya, identificar les tasques que realitza el psicopedagog i psicopedagoga en un centre, comptar amb l'opinió dels psicopedagogs sobre la seva tasca professional en els diversos àmbits d'actuació, fer propostes de millora en les accions i activitats desenvolupades per aquests professionals per tal d'atendre amb major grau d'eficàcia i eficiència la diversitat de l'alumnat present als centres de secundària en l'etapa d'educació secundària obligatòria, donar a conèixer la realitat del treball diari del psicopedagog i psicopedagoga, així com les demandes que fan per a que, tant equips directius com administració educativa, adoptin les mesures adients per atendre-les.

La primera part del llibre aborda els àmbits més teòrics que serveixen d'introducció per entendre la segona part on trobarem la part que ens aporta més informació i novetats del llibre: La investigació.

Van dissenyar un qüestionari amb la següent estructura:

1. Identificació del professorat

2. Atenció del psicopedagog i psicopedagoga a l'alumnat

\subsection{Docència}

2.2 Atenció individualitzada als alumnes amb NEE

3. Suport tècnic del psicopedagog/a al professorat

4. Suport del psicopedagog/a a l'acció tutorial, a l'orientació de l'alumnat i a les funcions de coordinació de l'acció tutorial

5. Desenvolupament professional del psicopedagog/a.

6. Valoració del psicopedagog/a sobre la seva figura professional 
Es va enviar a una mostra ampla de psicopedagogs i psicopedagogues d'instituts de tot Catalunya, en total 80 psicopedagogs i psicopedagogues, que desenvolupen la seva labor a l'etapa d'educació secundària obligatòria.

Aquest fet abastava moltes funcions i actuacions d'aquests professionals dels centre, i per tant, aportava informacions significatives per a la investigació.

Com a conclusions principals de la investigació, podríem dir en primer lloc que, tenint en compte les respostes que donen els enquestats quan contesten a les preguntes sobre si la funció del psicopedagog/a es valorada per la resta del professorat del centre i també considerant les dificultats que han assenyalat que estan presents quan inicien la seva tasca a un institut, trobem que la seva funció és prou coneguda i valorada, encara que hi ha un percentatge considerable que opinen el contrari.

Aquesta poca valoració que alguns psicopedagogs i psicopedagogues perceben envers la seva funció, tant per una part de la resta dels seus companys com per part de l'Administració, s'ha constatat en el fet que aquesta figura, malgrat estar perfectament definida i amb un perfil professional molt clar, no existeix en alguns del centres de secundària.

Els psicopedagogs i psicopedagogues no fan cap reivindicació de més temps per poder complir satisfactòriament totes les funcions que se'ls hi demana, malgrat ser força variades. Per a realitzar-les s'ajuden de variats recursos materials, destacant la utilització de programes informàtics, especialment, els programes i les orientacions que el Departament d'Ensenyament de la Generalitat de Catalunya posa a disposició per als professionals de l'educació.

Es valora com a positiu aquest suport que el Departament ofereix i que als psicopedagogs i psicopedagogues els hi va molt bé per a realitzar el seu treball.

Entre les tasques que realitzen, destaquen com a rellevants per aconseguir disminuir el fracàs escolar, les que persegueixen oferir una atenció individualitzada i personalitzada a l'alumnat amb necessitats específiques de suport educatiu, les activitats encaminades a donar suport i assessorament al professor tutor quan es troba amb una problemàtica que el supera $\mathrm{i}$ aquelles que tenen com a finalitat aconseguir una bona coordinació entre els professionals i que es treballi en equip.

El Ilibre és de lectura obligada de tots aquells professionals que es dediquen al món de la psicopedagogia, independentment de les funcions específiques que puguin determinar les instruccions d'inici de curs i de la tasca que faci al centre educatiu. Les reflexions a les que et condueix són interessants i poden ajudar a avançar als professionals que treballen en la funció psicopedagògica a l'ensenyament secundari independentment que ho facin des d'un servei educatiu com I'EAP o en un centre públic o privat.

Josep Maria Cornadó. Professor del Departament de pedagogia de la Universitat Rovira i Virgili. 